\title{
Applications of association rule mining in Teaching Evaluation
}

\author{
Li-hui Zhang ${ }^{1, a,{ }^{*},}$ Zhi-fang Lu ${ }^{2, b}$ \\ ${ }^{1}$ Undergraduate Teaching Quality Monitoring and Evaluation Center,Yunnan Normal University, \\ Yunnan, China \\ ${ }^{2}$ Kunming No.28 Middle School, Yunnan, China \\ azhanglihui169@126.com, b531760589@qq.com \\ ${ }^{*}$ Corresponding author
}

Keywords: Data mining, Association rule, Teaching Evaluation.

\begin{abstract}
Now the student's evaluation of teaching online is the most methods used in colleges and universities. Teaching Quality Evaluation System (TQES) has collected a lot of teaching information, but most of them have not been mined and researched very well. In this paper, the technique of associate rule mining is used to teaching information management of universities. The research analyze the data that evaluation of classroom teaching by student in teaching management. The experimental results show that the data mining is helpful for the teaching management.
\end{abstract}

\section{Introduction}

Evaluating the teaching standard of teachers, examining the teaching effect and improving the teaching process are essential parts of the overall quality assurance of education. Student satisfaction with the course is a crucial factor in the course design and delivery. The serialized record of quality evaluation of classroom teaching constitutes the big data. With massive amounts of data continuously being collected and stored, many universities are becoming interested in mining such patterns from their databases. The discovery of interesting correlation relationships among huge amounts of evaluating records can help in many teaching management decision-making processes. By adopting the instrument and method of data mining technology, these data will make a teacher's individual evaluation possible. Such a type of personalized evaluation, based on educational mining data can not only guarantee objectivity, but can also readjust teacher's teaching method accordingly. In this way, it will be easier for the teachers to have insight into each student's thoughts and facilitate the teaching management.

In this paper, it has chosen the students teaching evaluation data as study case about 2017-2018 the first semester of the academic year from the school of foreign languages \& literature, it can excavates the affect factors of the quality of teaching by using associate rule mining. So it can provide decision support for the teaching management departments, and guide teachers to carry out teaching works better, and improve their teaching quality.

\section{Data mining model of teaching evaluation in the university}

Suppose, as vice-president of teaching, you would like to learn more about the teaching effectiveness of teachers. Specifically, you wonder, "Which teacher has a good teaching effect?" To answer your question, teaching evaluation analysis may be performed on the students teaching evaluation data. You can then use the results to plan adjustment or decision-making.

If we think of the university as the set of items, then each item has a Boolean variable representing the presence or absence of that item. Each set can then be represented by a Boolean vector of values assigned to these variables. The Boolean vectors can be analyzed for teaching evaluation patterns that reflect items that are frequently associated. These patterns can be represented in the form of association rules. 


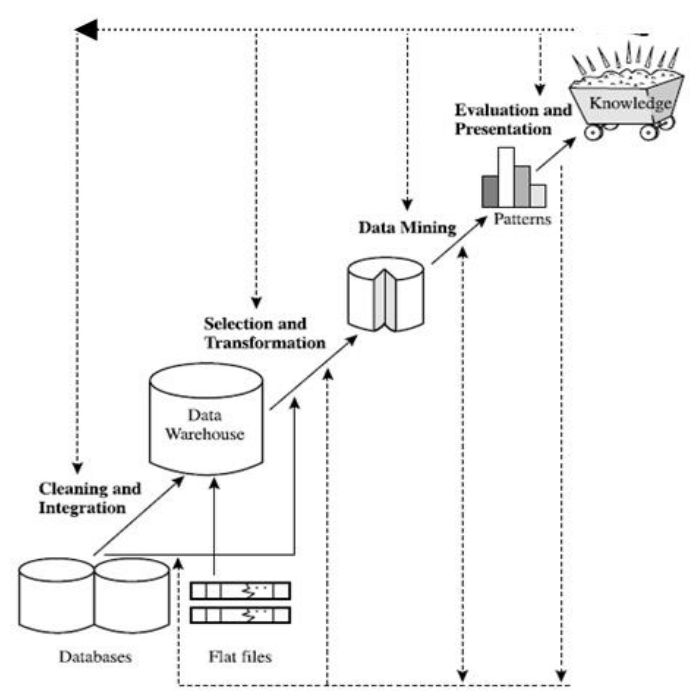

Fig. 1. Data mining of teaching evaluation

Data mining of teaching evaluation as a process is depicted in Figure 1 and consists of an iterative sequence of the following steps:

1. Data cleaning (to remove noise and inconsistent data, E.g. The number of students participating in teaching evaluation in some classes is too small, which affects the objectivity of teaching assessment. Therefore, this part of data is excluded. The validity of the original data has been handled: for example, low score thresholds, invalid coating, and high scores and low scores to improve the validity and accuracy of data.)

2. Data integration (where multiple data sources may be combined, Calculate each indicator score in each teacher's rating scale, According to the statistical theory, the student's score value basically accords with the normal distribution, that is, the objective numerical value is concentrated and the degree of dispersion is small.)

3. Data selection (where data relevant to the analysis task are retrieved from the database, include age, Professional title, Educational background, Evaluation Result)

4. Data transformation (where data are transformed or consolidated into forms appropriate for mining by performing summary, for instance. The conversion and merging of data refers to the processing of data, so as to construct a description form suitable for data mining. The title attribute is generalized and the age is discretized and converted into an age range. age $\leqslant 35,35 \leqslant$ age $\leqslant 46$, Age >46.)

5. Data mining (an essential process where intelligent methods are applied in order to extract data patterns)

6. Pattern evaluation (to identify the interestingness measures)

7. Knowledge presentation (where visualization and knowledge representation techniques are used to present the mined knowledge to the vice-president of teaching)

\subsection{Association rule}

This paper introduces the basic concepts of association rule mining for the discovery of interesting associations and correlations between itemsets in transactional and relational databases. The concept of association rules is proposed by Agrawal、Imielinski and Swami ${ }^{[1]}$, and refers to the interdependen -ce of data objects.

A rule is an expression of the form:

If Condition; then Result.

Here is an example taken from marketing:

If Nappies and Saturday; then Beer. ${ }^{[2]}$

Rule support and confidence are two measures of rule interestingness.

The support index is the probability

Prob(Condition and Result). 
The confidence index is the probability

$\operatorname{Prob}($ Condition and Result)/Prob(Condition).

\subsection{Association rule in teaching management decision-making}

This paper assumes minsup $=20 \%$ and minimum confidence inconf $=40 \%$ for the mining of association rules. The data mining association rules are used to process the data and the association rules are as follows:

Table 1 if support index <MinConf, indicating that the correctness of the rule is not high, out; support index $\geq$ MinConf, indicating that the rule has a higher actual value of use, output.

Table 1.Teaching evaluation information of 2017-2018 the first semester from the school of foreign languages \& literature

\begin{tabular}{|l|l|l|l|l|}
\hline $\begin{array}{c}\text { Teacher } \\
\text { id }\end{array}$ & \multicolumn{1}{|c|}{ age } & \multicolumn{1}{|c|}{$\begin{array}{c}\text { Professional } \\
\text { title }\end{array}$} & $\begin{array}{c}\text { Educational } \\
\text { background }\end{array}$ & \multicolumn{1}{|c|}{$\begin{array}{c}\text { Evaluation } \\
\text { Result }\end{array}$} \\
\hline 02 & 58 & Professor & Bachelor & 95 \\
\hline 08 & 35 & Lecturer & Master & 88 \\
\hline 17 & 38 & Professor & PhD & 93 \\
\hline 24 & 46 & Associate Professor & Master & 86 \\
\hline 28 & 51 & Professor & PhD & 92 \\
\hline 36 & 32 & Lecturer & Master & 78 \\
\hline 45 & 40 & Associate Professor & PhD & 84 \\
\hline 51 & 34 & Associate Professor & PhD & 92 \\
\hline$\ldots \ldots$ & $\ldots \ldots .$. & $\ldots . .$. & $\ldots \ldots$. & $\ldots .$. \\
\hline
\end{tabular}

We use Table 2 and Table 3 to analyse the relationship between teacher evaluation results and age and professional title.

Table 2. Age of Teaching evaluation information

\begin{tabular}{|l|c|c|}
\hline \multicolumn{1}{|c|}{ association rules } & support index & confidence index \\
\hline age $>46 \Rightarrow$ Evaluation Result=excellent & 0.28 & 0.66 \\
\hline $35 \leqslant$ age $\leqslant 46 \Rightarrow$ Evaluation Result=good & 0.20 & 0.51 \\
\hline age $<35 \Rightarrow$ Evaluation Result=general & 0.22 & 0.72 \\
\hline
\end{tabular}

The index of support indicates the degree of importance of the association rule for the overall data, and the index of confidence indicates the correctness of this rule. Obviously, the greater the value of the confidence, the more reliable the association rule. According to the association rule between the ages of Table 2 and the grades of evaluation of teaching, the following conclusions can be drawn: Senior teachers, the evaluation of students is high, and the results of the evaluation of teaching are excellent; middle-aged teachers, the evaluation of students is higher, and the results of evaluation are The number of students is good; while for young teachers, the evaluation of students is mostly in the middle. The association rule to a certain extent shows that the older, the richer the accumulation of teaching experience, the better the effect of teaching.

Table 3. Professional title of Teaching evaluation information

\begin{tabular}{|l|c|c|}
\hline \multicolumn{1}{|c|}{ association rules } & support index & confidence index \\
\hline $\begin{array}{l}\text { Professional title } \geqslant \text { Associate Professor } \\
\Rightarrow \text { Evaluation Result=excellent }\end{array}$ & 0.25 & 0.72 \\
\hline $\begin{array}{l}\text { Professional title=Associate Professor } \Rightarrow \\
\text { Evaluation Result=good }\end{array}$ & 0.21 & 0.51 \\
\hline $\begin{array}{l}\text { Professional title=Lecturer } \Rightarrow \\
\text { Evaluation Result=general }\end{array}$ & 0.24 & 0.71 \\
\hline
\end{tabular}

According to the association rules between the title and evaluation grades in Table 4, the following conclusions can be drawn: the grades of teachers with professional title are high, generally excellent; the grades with title of associate professor are high, and the results of evaluation are good. Most of the results of the teaching evaluation of the title teacher are ordinary. The rules show that there is a high degree of correlation between professional titles and evaluation grades, with higher grades for senior or vice-level appraisals and grades for mid-level appraisals. To a certain extent, the higher the job title 
is, the higher the rating is. Teachers who are called lecturers in their posts must also practice and learn more, and strive to improve their teaching level. The enlightenment of the above two association rules is: Class scheduling. The teacher's age and job title should be reasonably distributed so that students can maintain a good learning state of habit. At the same time, it can also encourage teachers to better carry out teaching work and improve teaching quality.

\section{Summary}

With the advent of education informatization, data information is continuously growing, and association rules in data mining technology are applied to the evaluation system of colleges and universities. It can not only objectively reflect the problems existing in teachers' teaching. Promote the further reform, development and improvement of the teaching staff, and it can also provide an effective basis for the leaders' macro decision-making.

\section{References}

[1] R. agrawal, T. lmielinski, A. swami. Mining association rules between sets of items in large databases[J]. Proceeding soft The ACM SIGMOD Conference on Management of data, pp. 207-216, May1993.

[2] DJ. hand. DataMining: statistics and More? The American Statistician, 1998, 52(2):112-118.

[3] Jiawei Han and Micheline Kamber, Data Mining Concepts and Techniques $2^{\text {nd }}$ edition 2006, pp. 591-648.

[4] Ste'phane Tuffe'ry, Data Mining and Statistics for Decision Making 2011, pp. 287-299. 